\title{
Urbanização e gestão do litoral centro-sul do estado de Santa Catarina
}

\section{Urbanization and management of middle south coast of Santa Catarina state}

\author{
M. SCHERER* \\ C. FERREIRA** \\ J. MUDAT*** \\ S. CATANEO ${ }^{* * * * *}$
}

\begin{abstract}
RESUMO
Trinta e seis municípios compõem o Litoral de Santa Catarina. Esses 36 municípios são divididos em cinco setores: norte, centro-norte, centro, centro-sul e sul. O litoral centro-sul é composto por seis municípios próximos do maior complexo lagunar do Estado. Laguna é o município que mais cresce nessa região do Estado, sendo também o município mais populoso. A urbanização acelerada e desordenada do litoral centro-sul, em especial a região de Laguna, vem causando impactos ambientais significativos na região, como poluição dos corpos hídricos, processos erosivos da região de dunas, perda de vegetação litorânea e de biodiversidade em geral. Atividades como a carcinicultura, agricultura, turismo e expansão urbana estão entre as atividades que mais contribuem para os impactos ambientais. Para que a região se desenvolva sem a perda de seus recursos naturais, algumas medidas devem ser tomadas, tais como: melhoria do saneamento básico; planificação do desenvolvimento urbano, levando em consideração a fragilidade das planícies costeiras e dunas frontais; zoneamento e definição de critérios para atividade de maricultura, em especial a carcinicultura; desenvolvimento e implementação de planos de manejo das unidades de conservação da região; seguimento da legislação ambiental, em especial as normas relacionadas à poluição de corpos hídricos e áreas de preservação permanente.

Palavras-chave: litoral de Santa Catarina; impactos ambientais; gestão costeira.
\end{abstract}

\footnotetext{
Laboratório de Ciências do Mar, Unisul.

Mestrando do Programa de Pós-Graduação em Engenharia Ambiental, UFSC.

Mestrando do Programa de Pós-Graduação em Geografia, UFSC.

Engenharia Sanitarista e Ambiental.
} 


\section{ABSTRACT}

Thirty six municipalities form the littoral of Santa Catarina State. These municipalities are divided in five sectors: north, center-north, center, center-south and south. Six municipalities belong to the centersouth littoral and in this sector is located the bigger coastal lagoon chain of the State. Laguna is the faster growing municipality in this region and has the highest number of inhabitants. The rapid and non-organized urbanization of this area has been causing remarkable environmental impacts such as water pollution, sand dune erosion, loss of coastal vegetation and biodiversity. Activities such as prawn farms, agriculture, tourism and urbanization are the most impacting activities. For a sustainable development of the region some actions should be taken, such as: sewage treatment, urban planning, aquiculture zoning, coastal ecosystems preservation, development and implementation of management plan for conservation areas, environmental laws enforcement.

Key-words: Santa Catarina coast; environmental impacts; coastal management.

\section{Introdução e caracterização geral da costa de Santa Catarina}

O litoral de Santa Catarina (sul do Brasil) se estende por 561,4 km, entre os paralelos $25^{\circ} 58^{\prime \prime}$ e $28^{\circ} 37^{\prime \prime} \mathrm{S}$ e os meridianos $48^{\circ} 25^{\prime \prime}$ e $48^{\circ} 49^{\prime \prime}$ W (MORAES, 1995) e tem 36 municípios costeiros, totalizando aproximadamente 9.094,4 $\mathrm{km}^{2}$ de área terrestre e $5.894 \mathrm{~km}^{2}$ de área oceânica. Os 36 municípios englobam uma população de 1.889 .474 habitantes, com uma densidade demográfica de $187 \mathrm{hab} / \mathrm{km}^{2}$ (GERCO/SC, 2004).

O litoral catarinense é orientado no sentido N-S desde a divisa com o Estado do Paraná até a altura do Cabo (Farol) de Santa Marta. O extremo sul do estado apresenta orientação SW-NE até a divisa com o estado do Rio Grande do Sul.

A zona costeira é representada por complexas formas de relevo de origem continental-marinha derivado de processos de acumulação durante o Cenozóico, e, principalmente, pelas oscilações do nível relativo do mar nos últimos 7.000 anos. É constituído por faixa alongada de terrenos suavemente planos, denominados de Planície Costeira, e limitado a leste pelo Oceano Atlântico. No nordeste do Estado, o relevo se sobressai na Serra do Mar, estendendo-se da divisa com o Paraná até a região sul-oeste de Joinville. No setor norte-centro-sul, o relevo apresenta feições marcantes das Serras do Leste Catarinense, que fazem parte de um segmento do Escudo Atlântico distribuído desde o sul do Vale do Rio Itapocu, ao norte, até o vale do Urussanga. No extremo sul do estado, o relevo da Serra
Geral marca a paisagem pelas escarpas do planalto basáltico (DNPM, 1987).

O estado de Santa Catarina é caracterizado por clima subtropical mesotérmico úmido, apresentando um inverno frio e um verão quente. Nas águas costeiras catarinenses ocorre o encontro da Corrente do Brasil, derivada da Corrente Sul Equatorial oriunda do continente africano, com a corrente das Malvinas, que é originada de um ramo da Corrente Circumpolar Antártica. O encontro dessas duas correntes é benéfico para o aumento da produtividade marinha na região sul do Brasil, influenciando também os ecossistemas terrestres. Assim, a biodiversidade e os ecossistemas da zona costeira catarinense apresentam um nítido gradiente norte-sul de substituição de espécies e fisionomias, com predominância de padrões tropicais no norte e subtropicais e temperados no sul. Esta condição agrega uma grande biodiversidade, sendo esta uma das principais peculiaridades regionais (PRONABIO, 1999).

Conforme o Programa Estadual de Gerenciamento Costeiro de Santa Catarina, o litoral é dividido em 5 setores, para efeitos de gestão. São eles: setor norte, centronorte, centro, centro-sul e sul (GERCO/sc, 2004).

O litoral norte do estado é caracterizado pela presença de uma grande baía, a Baía da Babitonga ou de São Francisco. Apresenta planície costeira com extensas praias e, mais ao sul, praias menores separadas por formações rochosas de basalto, gnaisse e granito, resultantes da pro- 
ximidade da Serra do Mar e da praia. Também apresenta baías e estuários, e grandes áreas de manguezais. Este trecho do litoral catarinense representa o pólo industrial do Estado, com importante porto interligado à rede ferroviária.

O litoral centro-norte é formado pela planície costeira e elevações das Serras do Leste Catarinense, terminando, a oeste, na Serra Geral. Neste trecho está presente a maior bacia hidrográfica da vertente atlântica, composta pelo Rio Itajaí, que nasce na Serra Geral a oeste e percorre as Serras do Leste e a Planície Costeira até desaguar no Oceano Atlântico. Este setor tem os municípios com maiores índices de densidade demográfica do estado, e um grande porto com elevada circulação de embarcações e consolidada atividade industrial e turística.

A região central do estado é caracterizada pela presença de rochas cristalinas pré-cambrianas, que interrompem a continuidade da planície costeira, formando pequenas praias, enseadas com costões rochosos, ramificações das Serras do Leste Catarinense. É nesse setor que se localiza a Ilha de Santa Catarina, maior ilha do estado e sede da cidade de Florianópolis, capital do estado de Santa Catarina.

O setor centro-sul apresenta uma paisagem formada por planícies costeiras e elevações das Serras do Leste Catarinense. Neste trecho do litoral está presente o maior complexo lagunar do Estado de Santa Catarina. A localidade do Farol de Santa Marta, no município de Laguna, é o ponto de alteração na orientação geográfica da linha de costa no litoral catarinense, sendo também o limite austral de espécies de mangue no litoral brasileiro. Ao sul desse município, os manguezais são totalmente substituídos por marismas.

A zona costeira do setor sul catarinense apresenta paisagem formada por grande planície cortada por rios, com presença de lagoas costeiras paralelas à linha de costa. A maior praia do estado, com aproximadamente $150 \mathrm{~km}$ de extensão, que se estende até a divisa com o estado do Rio Grande do Sul, também se localiza no litoral sul. Neste trecho estão presentes os maiores campos de dunas ativas do litoral catarinense.

\section{Caracterização da área de estudo}

A área a que se dedica esse estudo é a região centrosul do litoral do Estado de Santa Catarina. Essa área abrange seis municípios: Paulo Lopes, Garopaba, Imaruí, Imbituba, Laguna e Jaguaruna (Figuras 1 e 2).

Neste trecho, as Serras do Leste Catarinense são conhecidas pelo complexo da Serra do Tabuleiro, composto por extensa massa granitóide (Granitóide Pedras Grandes),

\section{FIGURA 1 - LOCALIZAÇÃO DA ÁREA DE ESTUDO NO ESTADO DE SANTA CATARINA}

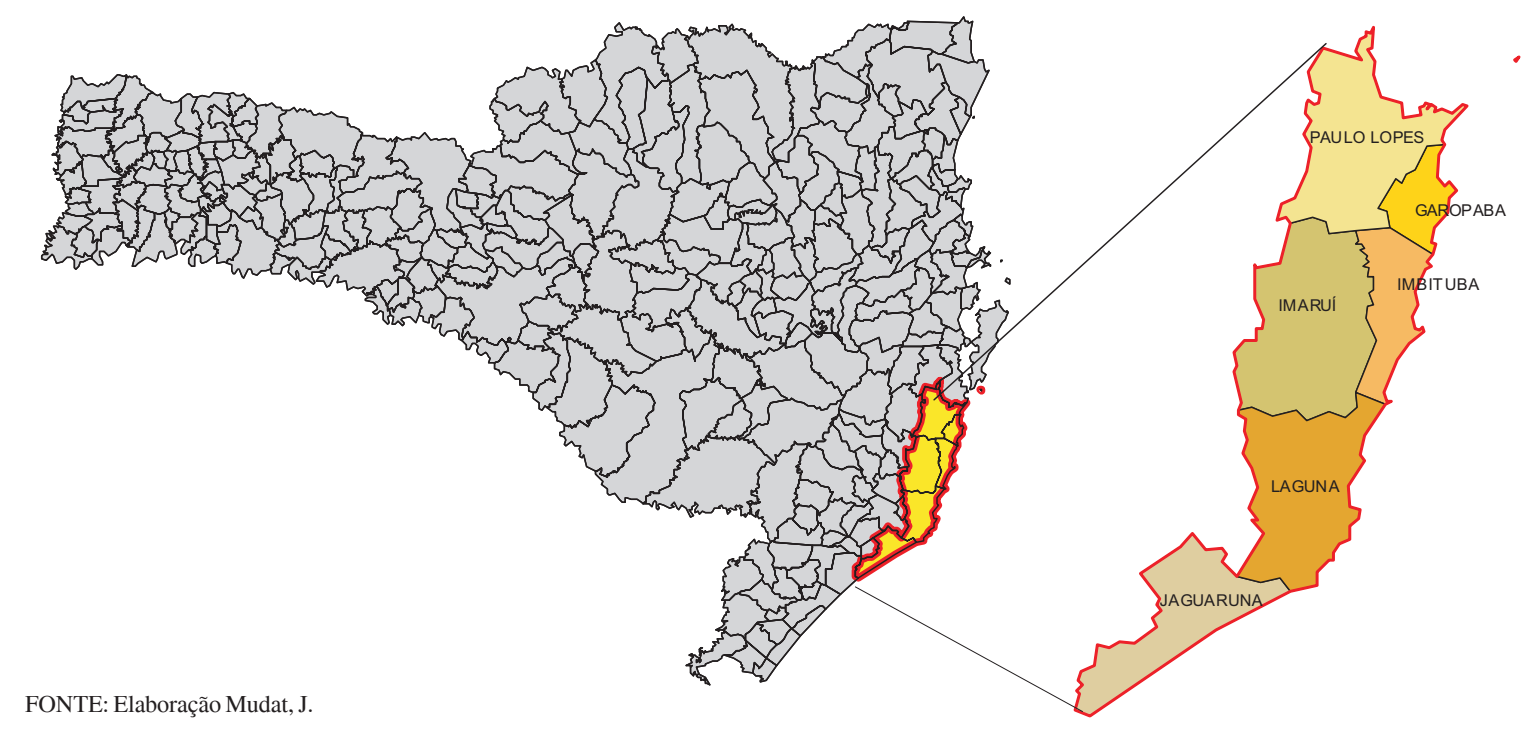


FIGURA 2 - LOCALIZAÇÃO DA ÁREA SOBRE IMAGEM DO SATÉLITE LANDSAT

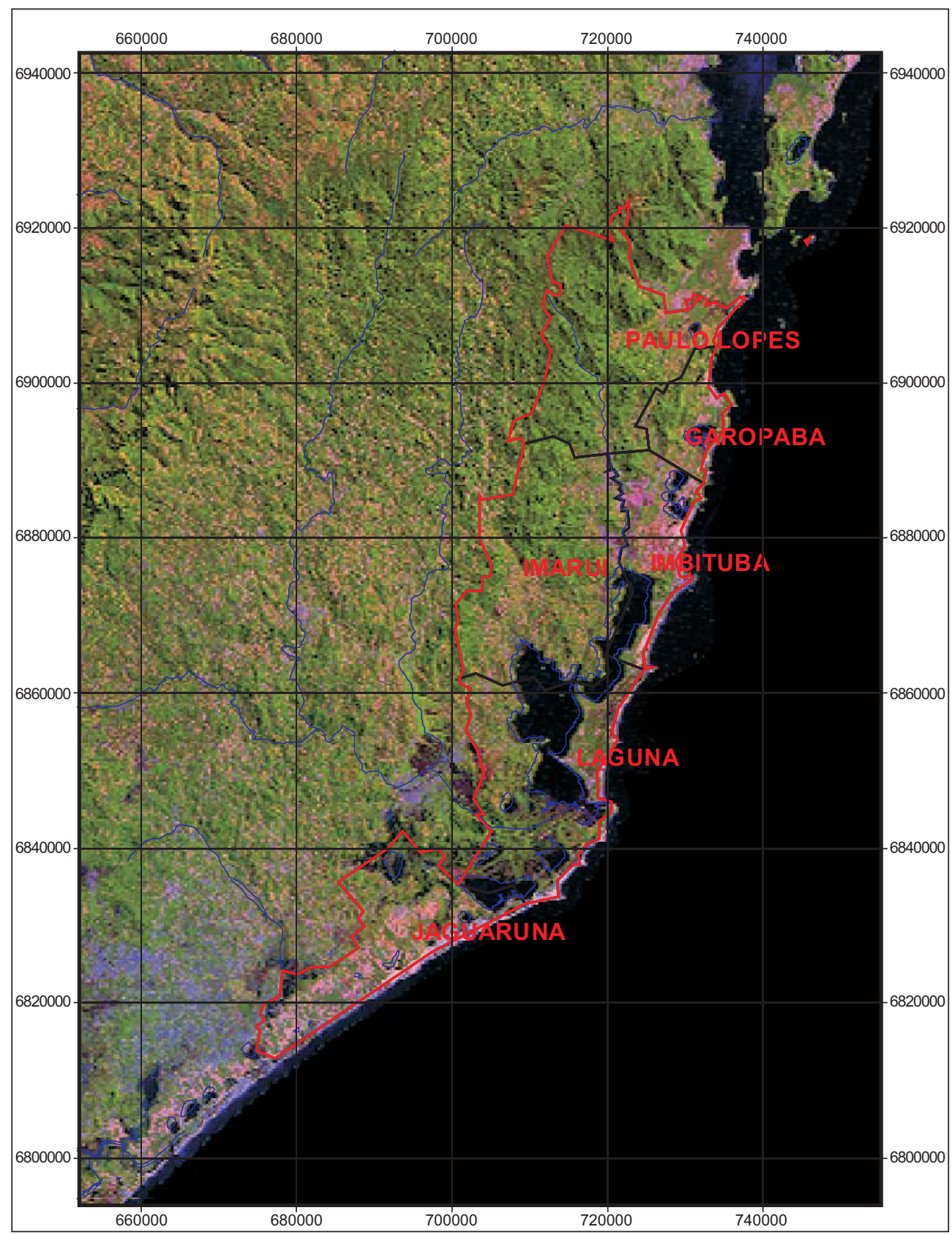

FONTE: Elaboração Julio Mudat com base em imagem de Satélite LandSat 
com limite norte no município de Palhoça, entendendo-se até a bacia do Rio Tubarão (DNPM, 1987).

A extensa planície costeira desse setor consiste em depósitos da Era Cenozóica, com presença de leques aluviais na porção interna (oeste) da planície, justaposta a rampas ancoradas sobre o embasamento cristalino e Serra Geral. Na porção externa da planície costeira (leste) se encontram sistemas deposicionais do tipo Ilha-Barreira, formados durante as oscilações do nível relativo do mar no Período Quaternário (CARUSO, 1995).

A planície costeira em questão apresenta dois níveis topográficos distintos, o relevo formado por terraços de construção marinha de idade Pleistocênica, originados das oscilações do nível do mar de 123.000 anos conhecidas como Transgressão Cananéia (suguio; MARTIN, 1978) e Penúltima Transgressão (BITTENCOURT et al., 1978). Este terraço de nível topográfico mais elevado apresenta grande similaridade com os depósitos Barreira III encontrados na costa do Rio Grande do Sul, descritos por Villwock et al. (1986), cujo nível médio do mar estava aproximadamente 8 +-2 m acima do nível atual (MARTIN; sUGUIO, 1986).

Fortes e Duarte (1996) observaram que as planícies da região apresentam feições de cristas com 8 a 9 m de altitude e depressões alongadas intracordões ou cavados com profundidade média de $3 \mathrm{~m}$, constituídos por areias de coloração amarronzada, apresentando-se compactadas e impregnadas de óxidos de ferro e geralmente recobertas por depósitos eólicos.

Na região em estudo, o sistema de deposição IlhaBarreira de idade pleistocênica condicionou a formação do sistema deposicional denominado por Caruso (1995) como Laguna-Barreira III, apresentando fácies eólicas compostas por camadas arenosas finas e muito finas de coloração avermelhada enriquecidas por argilas e óxidos de ferro e por fácies praiais marinhas, compostas por areias quartzosas finas a médias, com estratificações plano-paralelas com mergulho suave ao mar.

Os sistemas deposicionais Laguna-Barreira III e IV condicionaram na região a formação de diversos complexos lagunares e lagoas costeiras, menores ao norte (Lagoa do Ribeirão, no município de Paulo Lopes; Lagoa de Garopaba, no município de Garopaba; Lagoa de Ibiraquera, no município de Imbituba), e o maior complexo lagunar do estado, o de Laguna.

Este grande complexo lagunar abrange os municípios estudados neste artigo. A Lagoa do Mirim situa-se mais ao norte, e sua principal descarga hídrica é o Rio D’Una. A
Lagoa de Imaruí, a maior do complexo, apresenta área de $86,32 \mathrm{~km}^{2}$ e tem como maiores contribuintes o Rio Aratingaúba e o Rio Sirqueiro (INPH, 1994). A Lagoa Santo Antonio apresenta área de $33,85 \mathrm{~km}^{2}$ e recebe aporte hídrico dos Rios Tubarão e Sambaqui, com comunicação permanente com o mar pela Barra de Laguna, que apresenta molhes na forma de enrocamento rochoso. A Lagoa de Santa Marta, cujo principal contribuinte hídrico é o Rio do Meio, apresenta ligação com o sistema lagunar Santo AntônioImaruí e Mirim ao norte, e ao sul com o sistema lagunar Camacho-Laranjal-Garopaba do Sul.

\section{Processo de desenvolvimento urbano e indicado- res de qualidade no litoral centro-sul}

O crescimento urbano no litoral centro-sul do estado de Santa Catarina iniciou-se no município de Laguna, primeira cidade da região. Em 1496, os portugueses e espanhóis dividiram seus respectivos territórios do novo continente por meio do Tratado de Tordesilhas, incidindo sobre Laguna o limite austral das terras portuguesas.

Para fins de proteção das terras e expansão da fronteira para as proximidades da Foz do Rio Prata, foi iniciada a colonização da região. Em 1684 foi fundado o povoado de Santo Antonio dos Anjos de Laguna, base militar e pólo de colonização. Elevada à categoria de Vila em 1714, passa a ter função importante no escoamento da produção agrícola e pecuária, pelo porto, para o Rio de Janeiro. Na metade do século XVII, com migração açoriana, o incremento da atividade portuária e comercial dá inicio à urbanização do município de Laguna (LUCENA, 1998).

Nos fins do século XVIII e início do século XIX, o porto de Laguna passa a exportar outra mercadoria, além de produtos agrícolas e pecuaristas: carvão extraído na região de Lauro Miller e Criciúma. A exportação desse produto mineral gerou várias obras, como a Ponte de Cabeçudas, por onde passava a estrada de ferro Dona Teresa Cristina, iniciada em 1881. Durante a $1^{\mathrm{a}}$ Guerra Mundial, Laguna teve impulso de caráter econômico com o carvão, mas, na $2^{\mathrm{a}}$ Guerra Mundial, perdeu lugar para o Porto de Imbituba, que tinha maior calado para navios maiores e que se beneficiou da finalização da estrada de ferro Dona Teresa Cristina.

A expansão urbana no município de Laguna ocorre com o surgimento da BR-101, que vem para interligar Santa Catarina aos estados vizinhos pelo litoral, em meados da 
década de 1950. O traçado urbano se expande para duas direções distintas: primeiramente ao longo da estrada de ligação do perímetro central, a BR-101, inicialmente ocupada por população de média-baixa renda (pescadores, trabalhadores do comércio, construção civil, etc.), e em seguida para a Praia do Mar Grosso, que se tornou um bairro nobre e favoreceu o incremento da atividade turística.

Em 1978 foi elaborado o primeiro Plano Diretor de Laguna, sendo decretados os primeiros tombamentos de imóveis históricos. Localizada $120 \mathrm{~km}$ ao sul da capital Florianópolis, Laguna abriga 47.568 habitantes (IBGE, 2000).

O litoral centro-sul de Santa Catarina apresenta um crescimento demográfico considerável, principalmente na região da cidade de Laguna. Esse crescimento traz deman- das de infra-estrutura, moradia e alternativas econômicas.

Levando-se em consideração que a densidade demográfica média do estado de Santa Catarina é de 61,53 $\mathrm{hab} / \mathrm{km}^{2}$ (IBGE, estimativa para 2005), alguns dos municípios do litoral centro-sul apresentam alta densidade demográfica (ex: Imbituba, com 193,20 hab/km²; Garopaba, com 114,80 hab $/ \mathrm{km}^{2}$; e Laguna, com 107,98 hab/km²). Estes são, coincidentemente, os municípios de maior afluxo de turistas no período de veraneio e têm a maior taxa de urbanização (Tabela 1) (IBGE, 2000), sendo também, historicamente, os municípios de maior número de habitantes (Tabela 2 , Gráfico 1). Na Tabela 2 também se pode observar que Laguna é o município que mais cresceu nessa região do estado ao longo de 40 anos, sendo também o município mais populoso, apresentando 47.568 habitantes (IBGE, 2000) (Figura 3).

TABELA 1 - POPULAÇÃO DOS MUNICÍPIOS DO LITORAL CENTRO SUL - SC 2000

\begin{tabular}{|c|c|c|c|c|c|c|c|}
\hline Municípios & Pop. total & Pop. rural & $\%$ & Pop. urb. & Área do mun. $\mathrm{km}^{2}$ & $\begin{array}{c}\text { Dens. dem. } \\
\left(\mathrm{hab} / \mathrm{km}^{2}\right)\end{array}$ & Tx. urban. $(\%)$ \\
\hline Paulo Lopes & 5.924 & 2.370 & 40,01 & 3.554 & 450,372 & 13,15 & 59,99 \\
\hline Garopaba & 13.164 & 2.442 & 18,55 & 10.722 & 114,670 & 114,80 & 81,45 \\
\hline Imbituba & 35.700 & 1.173 & 3,29 & 34.527 & 184,787 & 193,20 & 96,71 \\
\hline Laguna & 47.568 & 10.284 & 21,62 & 37.284 & 440,525 & 107,98 & 78,38 \\
\hline $\mathrm{SC}$ & 5.356 .360 & 1.138 .429 & 21,25 & 4.217 .931 & $95.346,181$ & 56,18 & 78,75 \\
\hline
\end{tabular}

FONTE: Elaborada por Cataneo, S. com base em IBGE, 2000 - Censo Demográfico.

TABELA 2 - POPULAÇÃO DOS MUNICÍPIOS DO LITORAL SUL - SC DE 1960 A 2000

\begin{tabular}{l|c|c|c|c|c}
\hline \multicolumn{5}{|c}{ POPULAÇ̃̃O } \\
\hline Municípios & 1960 & 1970 & 1980 & 1991 & 2000 \\
\hline Paulo Lopes & 4.265 & 5.711 & 5.491 & 5.530 & 5.924 \\
\hline Garopaba & 6.620 & 7.458 & 8.237 & 9.918 & 13.164 \\
\hline Imaruí & 14.488 & 21.041 & 18.970 & 15.431 & 13.404 \\
\hline Imbituba & 10.878 & 20.498 & 25.148 & 30.942 & 35.700 \\
\hline Laguna & 18.763 & 35.042 & 39.519 & 44.862 & 47.568 \\
\hline Jaguaruna & 9.126 & 14.397 & 14.695 & 18.427 & 14.613 \\
\hline Litoral Centro Sul & 64.140 & 104.147 & 112.060 & 125.110 & 130.373 \\
\hline SC & 2.129 .252 & 2.805 .447 & 3.627 .933 & 4.541 .994 & 5.356 .360 \\
\hline
\end{tabular}

FONTE: Elaborada por Cataneo, S. baseado em IBGE - Censos de 60, 70, 80, 91 e 2000. 
No mosaico de fotografias aéreas atuais da região de Laguna (Figura 4) observa-se que as planícies costeiras de solo drenado estão praticamente todas ocupadas pela malha urbana.

No que concerne à riqueza da região, o litoral centrosul de Santa Catarina tem um produto interno bruto (PIB) per capita considerado baixo, com um índice de 0,06 (Tabela 3). Mesmo com um desempenho econômico considerado baixo e uma renda per capita abaixo da média do estado $\mathrm{R} \$ 268,38$ para o litoral centro-sul e R \$ 349,32 para Santa Catarina, segundo a Tabela 5 -, o índice de desenvolvimento humano (IDH) é considerado de médio a alto pela Secretaria de Estado do Desenvolvimento Social, Urbano e Meio Ambiente (atual SDS). Esse índice para o litoral centro-sul é de
0,799, sendo 0,796 o índice encontrado para Santa Catarina (Tabela 4) e 0,792 para o Brasil, segundo o Relatório de Desenvolvimento Humano (RDH) emitido em 7 de setembro de 2005 pelo PNUD. Também segundo esse relatório, a taxa de alfabetização no Brasil é de $88,4 \%$, e o país ocupa o $91^{\circ}$ lugar no ranking mundial realizado pelo PNUD, que engloba 177 países. Santa Catarina tem uma taxa média de alfabetização maior, de 94,3\% (IBGE, 2000), mas a região do litoral centro-sul tem uma média ligeiramente superior à brasileira, com $87,6 \%$ de adultos alfabetizados. Nesse contexto, os municípios de Laguna e Imbituba - dois dos mais populosos da região - se destacam, juntamente com o município de Jaguaruna, por apresentarem taxa de alfabetização acima de 90\% (Tabela 5).

GRÁFICO 1 - CRESCIMENTO DO NÚMERO DE HABITANTES NOS MUNICÍPIOS DO LITORAL CENTRO-SUL

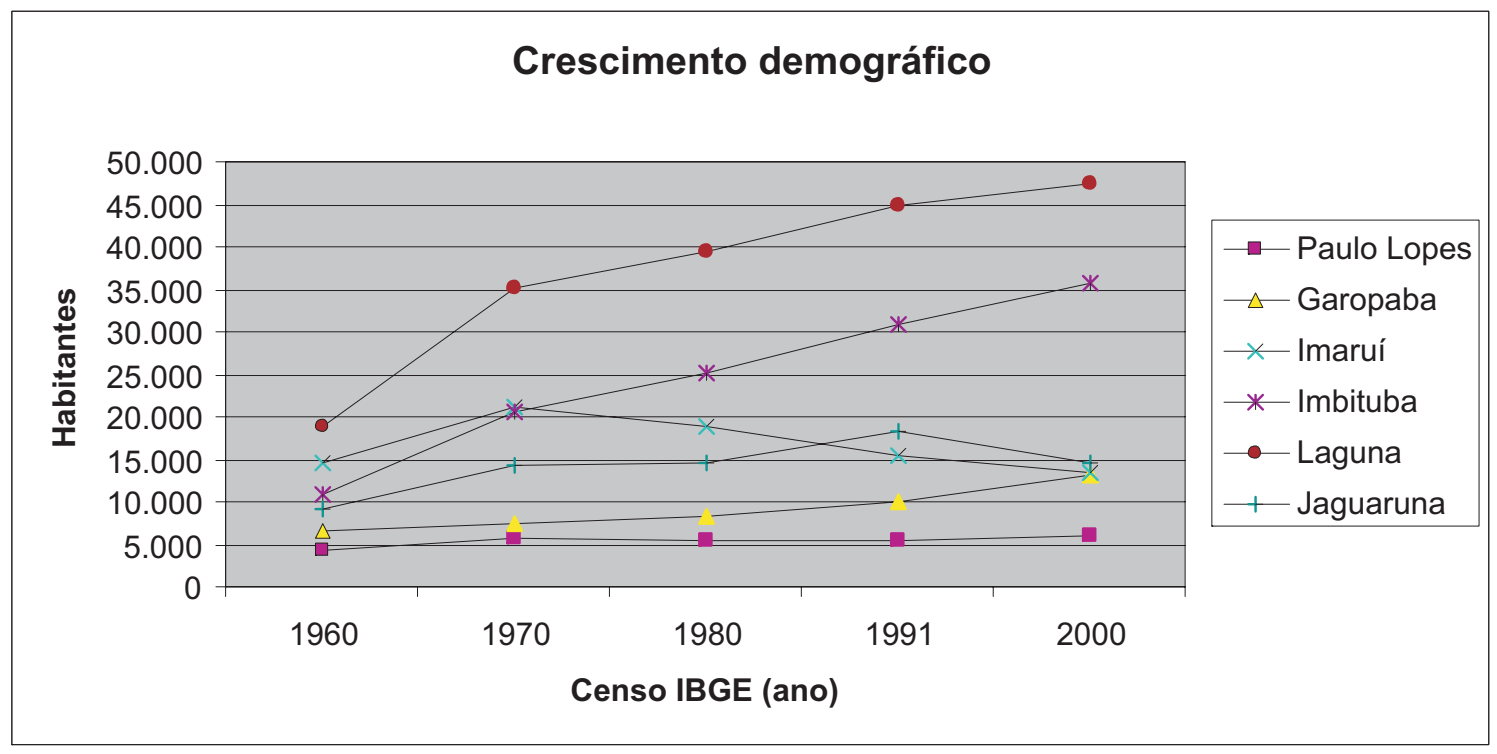

FONTE: Elaboração Ferreira, C.M. com base nos dados da Tabela 2. 
FIGURA 3 - NÚMERO DE HABITANTES POR MUNICÍPIO DO LITORAL CENTRO-SUL

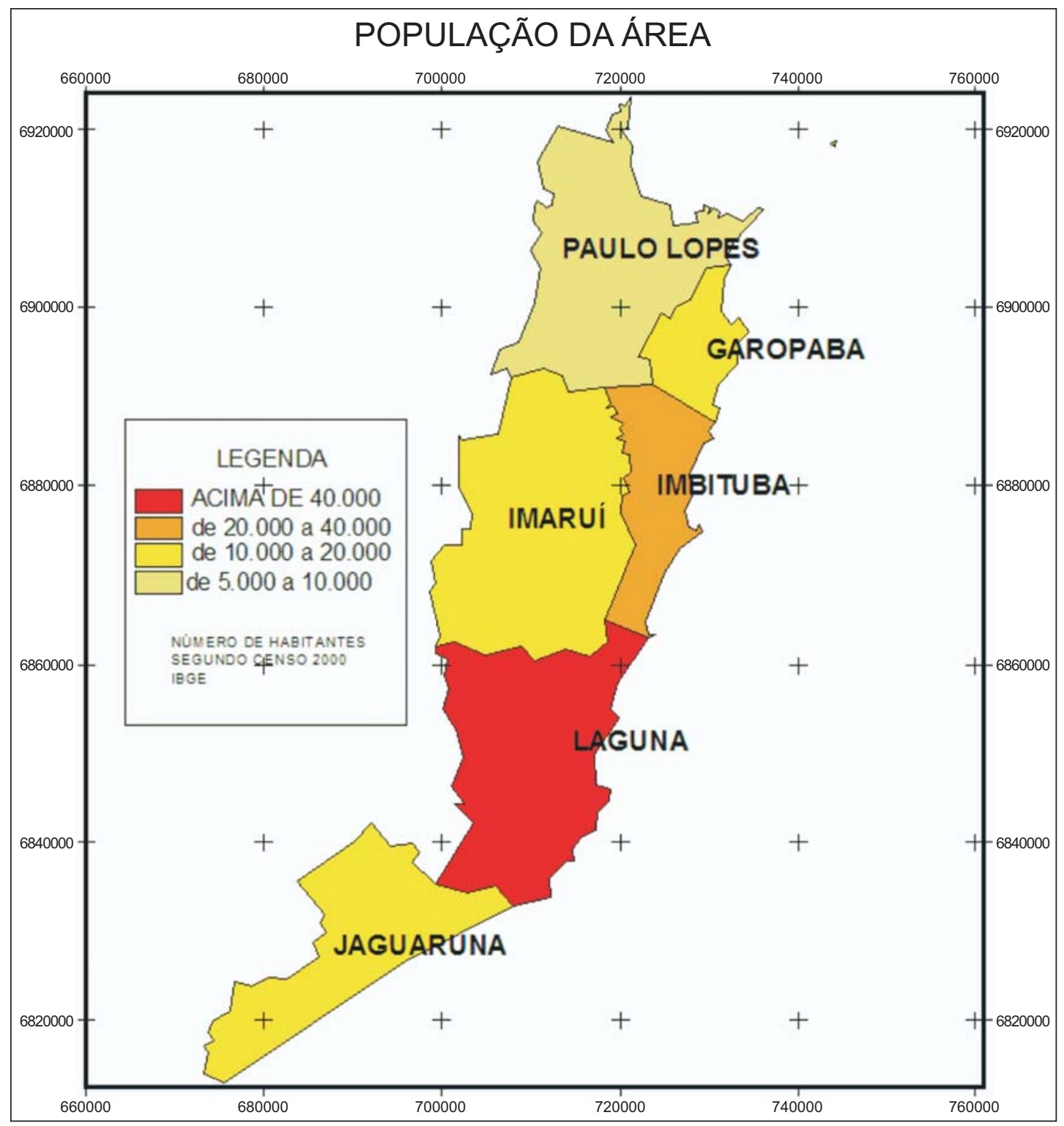

FONTE: Elaboração Mudat, J. 
FIGURA 4 - MOSAICO DE FOTOGRAFIAS AÉREAS DA REGIÃO DE LAGUNA (2004)

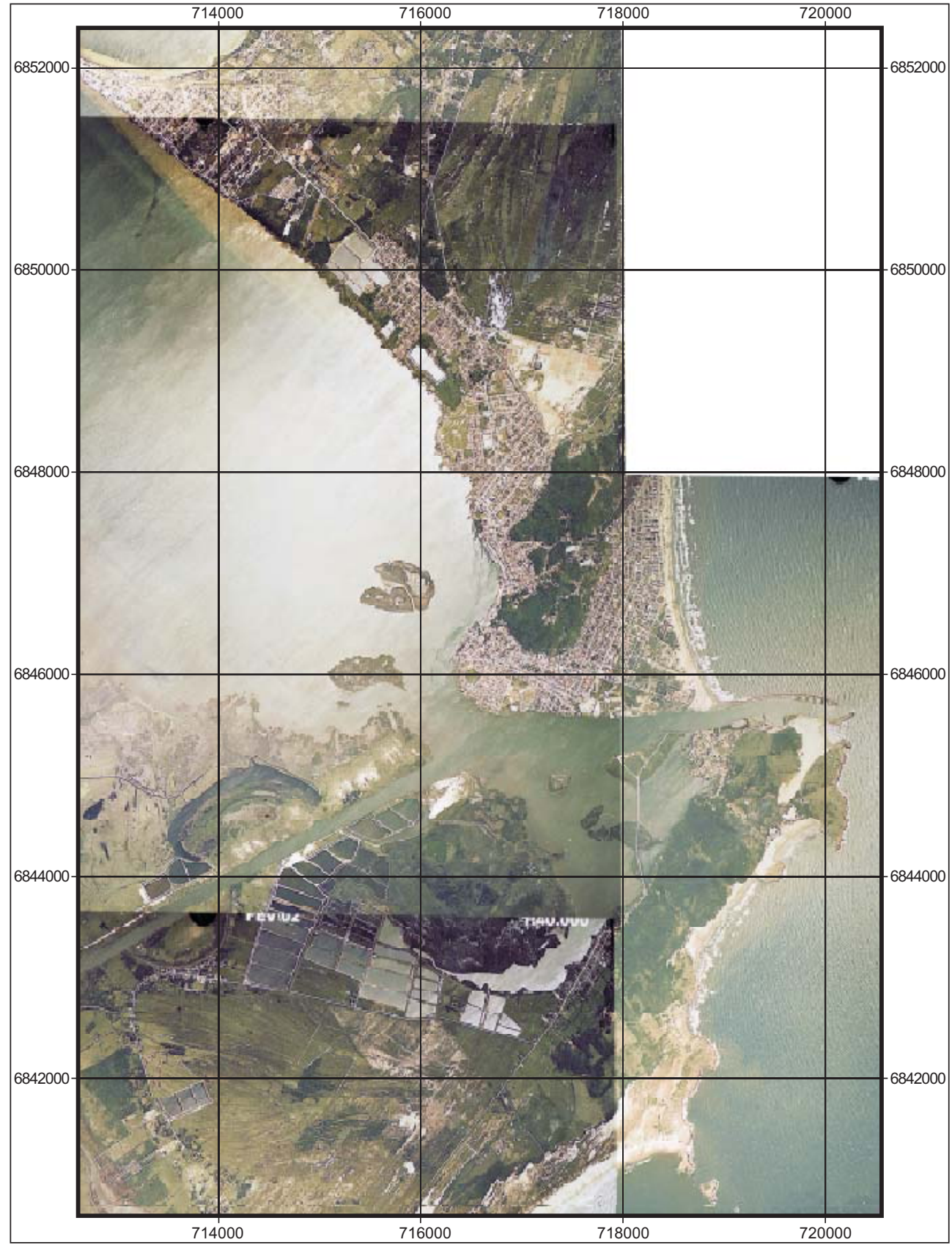

FONTE: Elaboração Mudat, J. com base em DNPM, 2004. 
TABELA 3 - ESTIMATIVA DO PIB PER CAPITA, SEGUNDO O VALOR FISCALA PREÇOS DE 1999 (IGP/DI - FGV)

\begin{tabular}{|c|c|c|c|c|c|c|}
\hline \multirow[t]{2}{*}{ Município } & \multicolumn{4}{|c|}{ PIB per capita $(\mathrm{R} \$ 1,00 / \mathrm{hab})$} & \multirow[t]{2}{*}{ Índice } & \multirow[t]{2}{*}{ Condição de Eficiência } \\
\hline & 1996 & 1997 & 1998 & 1999 & & \\
\hline Paulo Lopes & 1.687 & 1.390 & 1.544 & 1.566 & 0,05 & Baixa \\
\hline Garopaba & 1.020 & 1.140 & 1.204 & 1.080 & 0,01 & Baixa \\
\hline Imaruí & 551 & 629 & 710 & 681 & 0,00 & Baixa \\
\hline Imbituba & 3.381 & 2.721 & 2.840 & 2.983 & 0,16 & Baixa \\
\hline Laguna & 1.202 & 1.245 & 1.297 & 1.285 & 0,03 & Baixa \\
\hline Jaguaruna & 2.845 & 2.784 & 2.924 & 2.858 & 0,15 & Baixa \\
\hline Litoral Centro Sul & 10.686 & 9.909 & 10.519 & 10.453 & 0,06 & Baixa \\
\hline Santa Catarina & 7.540 & 7.378 & 7.364 & 7.370 & - & - \\
\hline
\end{tabular}

FONTE: Elaborada por Cataneo, S. com base na Secretaria de Estado da Fazenda - SC, IBGE e FGV.

OBS.: O PIB de 1996 a 1998 foi calculado a partir do valor adicionado.

O PIB de 1999 foi calculado levando-se em consideração a média aritmética do VAF dos anos de 1996 a 1998.

Valores a preço de 1999.

VAF - Valor Adicionado Fiscal.

PIB Per capita $=$ Valor Adicionado Municipal * PIB de SC / Valor adicionado SC / População do Município.

TABELA 4 - IDH - ÍNDICE DE DESENVOLVIMENTO HUMANO

\begin{tabular}{l|c|c|c|c}
\hline \multicolumn{1}{c|}{ Municípios } & 1970 & 1980 & 1991 & 2000 \\
\hline Paulo Lopes & 0,353 & 0,529 & 0,567 & 0,744 \\
\hline Garopaba & 0,325 & 0,520 & 0,605 & 0,817 \\
\hline Imaruí & 0,357 & 0,515 & 0,619 & 0,674 \\
\hline Imbituba & 0,397 & 0,676 & 0,712 & 0,891 \\
\hline Laguna & 0,418 & 0,620 & 0,671 & 0,868 \\
\hline Jaguaruna & 0,408 & 0,600 & 0,660 & 0,800 \\
\hline Litoral Centro Sul & 0,376 & 0,577 & 0,639 & 0,799 \\
\hline SC & 0,477 & 0,734 & 0,785 & 0,796 \\
\hline
\end{tabular}

\begin{tabular}{|l|}
\hline 0,800 a $1,000=$ alto \\
\hline 0,650 a $0,799=$ médio alto \\
\hline 0,500 a $0,649=$ médio \\
\hline 0,300 a $0,499=$ médio baixo \\
\hline 0,000 a $0,299=$ baixo \\
\hline
\end{tabular}

FONTE: Elaborada por Cataneo, S. com base em dados da SDS.

TABELA 5 - INDICADORES DE SAÚDE, EDUCAÇÃO E RENDAE SUA POSIÇÃO EM SANTA CATARINA

\begin{tabular}{|c|c|c|c|c|c|}
\hline Município & $\begin{array}{c}\text { Esperança de vida } \\
\text { ao nascer (anos) }\end{array}$ & $\begin{array}{l}\text { Taxa de alfabetização } \\
\text { de adultos }(\%)\end{array}$ & $\begin{array}{c}\text { Taxa bruta de freqüência } \\
\text { escolar }(\%)\end{array}$ & $\begin{array}{l}\text { Renda per capita } \\
\text { mensal (R\$) }\end{array}$ & Posição em SC \\
\hline Paulo Lopes & 74,8 & 83,0 & 74,8 & 184,28 & 239 \\
\hline Garopaba & 75,1 & 86,0 & 79,6 & 234,03 & 184 \\
\hline Imbituba & 74,7 & 91,4 & 85,3 & 248,42 & 104 \\
\hline Laguna & 73,3 & 91,5 & 81,7 & 247,23 & 161 \\
\hline $\mathrm{SC}$ & - & - & - & 349,32 & - \\
\hline
\end{tabular}

FONTE: Elaborada por Cataneo, S. com base em dados da SDS. 


\section{Principais usos do solo e atividades e suas impli- cações ambientais no litoral centro-sul de Santa Catarina}

Vários usos do solo e atividades são desenvolvidos na zona costeira centro-sul do estado de Santa Catarina. Segundo a Secretaria de Desenvolvimento Urbano e Meio Ambiente do Estado de Santa Catarina (SDM, atual SDS), no seu trabalho de Caracterização dos ativos ambientes da zona costeira catarinense, publicado em MMA (1998), os principais usos e atividades realizados nos ecossistemas e ambientes do litoral são: atividade portuária, industrial, agrícola, aqüicultura, extração mineral e vegetal, pesca, reflorestamento, turismo, recreação e urbanização (Tabela 6).

Segundo Gerco/SC (1999), a exploração descontrolada das florestas originais do litoral centro-sul, para usos da madeira na construção civil, fabricação de móveis e lenha, a implantação de áreas de cultivo e pastagens, e a extração de carvão reduziram a cobertura vegetal.

Dados do IBGE (2000) demonstram que a região do delta do Rio Tubarão é utilizada para o cultivo de arroz irrigado, feijão, fumo, mandioca e milho. Atualmente, a extração de conchas marinhas e argilas para a fabricação de cal e cerâmica, assim como a atividade de carcinicultura, são as mais recentes atividades socioeconômicas desenvolvidas na região.

A faixa litorânea da região, formada por extensas planícies próximas ao mar, é imprópria para a agricultura pela salinidade e pobreza do solo, mas apresenta excelentes condições para implantação de fazendas de cultivo marinho.
Portos e transporte

A principal rodovia que percorre todo o litoral centro-sul de Santa Catarina é a BR-101, que conecta os portos de São Francisco do Sul, Itajaí, Imbituba e Laguna. O oeste do estado é ligado ao litoral pelas rodovias BR-163, 282 e 470 . O sistema ferroviário restringe-se a carga e transporta as mercadorias entre Laguna e Tubarão (COSTA, 1995).

Na região centro-sul, os dois portos mais importantes são o porto de Imbituba e o porto pesqueiro de Laguna.

As atividades impactantes derivadas dos meios de transporte passam pelo desmatamento de grandes áreas de vegetação de restinga e de mata atlântica, soterramento de manguezais e lagoas costeiras a alteração da dinâmica costeira por meio de molhes e enrocamento.

Essas atividades podem levar à perda de hábitats e conseqüente perda de biodiversidade, poluição de recursos hídricos, erosão costeira, para listar alguns impactos negativos.

\section{Agricultura}

O setor agrícola é uma importante atividade econômica para Santa Catarina, responsável por 17,4\% do PIB catarinense, e as culturas mais representativas no litoral são o milho, o feijão, o fumo, a batata, o arroz e, em menor escala, o tomate, a banana e a cebola (SDM, 1997).

A região costeira não é a que mais se destaca nessa atividade, com uma produção menor que a região oeste do estado. No entanto, a expansão das áreas agrícolas, princi-

TABELA 6 - ESTRUTURA DAS ATIVIDADES ECONÔMICAS DO VALOR ADICIONADO BRUTO A PREÇO BÁSICO EM SANTA CATARINA (\%)

\begin{tabular}{l|c|c|c|c}
\hline & 1997 & 1998 & 1999 & 2000 \\
\hline Agopecuária & 12,84 & 12,85 & 13,88 & 13,77 \\
\hline Indústria & 35,88 & 35,63 & 37,86 & 38,31 \\
\hline Comércio & 6,69 & 6,87 & 6,62 & 5,80 \\
\hline Demais Atividades & 44,59 & 44,65 & 41,64 & 42,12 \\
\hline Total & 100 & 100 & 100 & 100 \\
\hline
\end{tabular}

FONTE: Elaborada por Cataneo, S. com base em dados da SDS/MMA, 1998. 
palmente para a cultura do arroz, vem prejudicando as matas de planície costeira na região sul, determinando-as como um dos ecossistemas costeiros mais ameaçados. Além disso, os ecossistemas de lagoas e banhados ocupados pelas aves migratórias e aves locais são também intensamente pressionados pelas lavouras de arroz. Paradoxalmente, no entanto, essa atividade favorece algumas espécies de aves aquáticas que utilizam o arroz para alimentação, nidificação e abrigo, o que gera conflitos com produtores rurais pelos supostos danos causados às lavouras.

O problema ambiental que a cultura de arroz pode acarretar em Santa Catarina também ocorre pela utilização indiscriminada de agrotóxicos e pesticidas que vêm a comprometer os cursos de água. A contaminação dos rios e do lençol freático por substâncias tóxicas acaba atingindo a zona costeira.

\section{Aqüicultura}

O litoral de Santa Catarina vem se firmando cada vez mais como um dos maiores pólos de maricultura. $\mathrm{O}$ cultivo de moluscos está bem representado na região central do litoral de Santa Catarina, em Porto Belo, Ilha de Santa Catarina e região de Palhoça e Paulo Lopes.

O cultivo de camarão em cativeiro (carcinicultura) é uma atividade em pleno desenvolvimento na região centrosul do litoral do estado. A principal área de desenvolvimento da carcinicultura é o complexo lagunar da região de Laguna. Na Figura 4 observa-se que na desembocadura do Rio Tubarão existem inúmeras fazendas de cultivo de camarão.

Os impactos ambientais dessas atividades na costa catarinense ainda não foram devidamente estudados, mas pode-se inferir que a alteração de ambientes naturais para a instalação de tanques, assim como a mudança de cursos de água, tem a capacidade de interferir na ecologia da zona costeira. Tampouco foram devidamente estudados os possíveis impactos advindos da concentração de produtos como ração e antibióticos na água do cultivo que porventura venha a ter contato com a água do complexo lagunar.

A utilização da lâmina de água por cultivadores também pode ser considerada um impacto ambiental e social importante, que tem gerado conflitos entre pescadores artesanais, turistas e donos de cultivos.

\section{Pesca e extração de recursos vivos marinhos}

Graças à abundância de espécies de valor econômico e à morfologia favorável do litoral de Santa Catarina, a pesca se desenvolve como uma atividade tradicional neste estado. Segundo relatório da Petrobras (1994), os principais recursos pesqueiros explorados em Santa Catarina incluem: papa-terras e pescadas (Sciaenidae), cação (Triakidae), gordinho (Stromateidae), bagre (Ariidae), chicharro e pampo (Carangidae), cocoroca (Pomadasyidae), linguado (Bothidae) e sardinha (Clupeidae), constituindo o recurso sujeito a maior esforço de pesca de Itajaí e Navegantes. Também muito utilizadas são a tainha (Mugilidae), a anchova (Pomatomidae) e a corvina (Sciaenidae).

Dentro do grupo dos crustáceos, as espécies mais importantes economicamente são: Farfantepenaeus paulensis (camarão-rosa) e Xiphopenaeus kroeyer (camarão sete-barbas). Essas espécies penetram em lagunas e estuários para crescer e voltam ao mar na época da reprodução.

Segundo dados do Instituto do Milênio - Projeto Recursos Costeiros (Recos) (2004), a pesca artesanal em Santa Catarina conta com aproximadamente 38.792 pescadores e 6.137 embarcações. Os principais recursos desse tipo de pesca são: corvina (Micropogonias furnieri) na região centro-sul, e camarão sete-barbas (Xiphopenaeus kroeyeri) na região norte.

Ainda segundo o Projeto Recos (2004), a pesca industrial ocorre principalmente no porto de Itajaí, e na região centro-sul esse tipo de pesca ocorre em Laguna. O número aproximado de pescadores é de 7.900, em aproximadamente 900 embarcações.

Os principais recursos da pesca industrial são: sardinha-verdadeira (Sardinella brasiliensis), bonito (Katsuwonus pelamis), camarões sete-barbas, rosa e santana (Xiphopenaeus kroeyer, Farfantepenaeus paulensis, Pleuticus muellerii) e a tainha (Mugil planatus), capturada por pescadores artesanais e industriais de todo o litoral.

Como a costa catarinense é exposta ao mar, a pesca se concentra nas regiões litorâneas praiais e intralagunares, o que leva muitas vezes à sobreexploração dos recursos e de seus hábitats, levando a um decréscimo da própria pesca. Além disso, os sistemas lagunares estão sendo poluídos por indústrias e mineração, e essa poluição já afetou a 
produção de pescado na região sul de Santa Catarina. Em 1976, um pescador do sul capturava $15 \mathrm{~kg}$ de pescado por dia, na época da safra; em 1982, essa média já caiu para $4,2 \mathrm{~kg}$ por dia.

\section{Saneamento básico}

A região centro-sul do Estado apresenta índices de cobertura de saneamento básico baixos. Segundo IBGE (2000), os índices relativos à cobertura de abastecimento de água, coleta de lixo e esgotamento sanitário estão inferiores à média estadual, que já é baixa em relação à média nacional.

Os municípios da região do litoral centro-sul apresentam, em média, $62 \%$ das residências cobertas pela rede pública de abastecimento de água, com destaque para Imbituba e Laguna, que apresentam o maior índice de abas- tecimento público, com $74 \%$ e $69 \%$, respectivamente. O menor índice de abastecimento pela rede pública de água é encontrado em Jaguaruna, com apenas $26 \%$ de cobertura (Tabela 7).

Segundo a Companhia Catarinense de Águas e Saneamento (Casan) (2004), o abastecimento de água da cidade de Laguna é realizado com a água do manancial da Lagoa do Gi e, em Imbituba, com água do manancial do Rio D’Una.

A coleta de lixo também se mostra ineficiente em alguns municípios, como no caso do município de Imaruí, ou apenas regular (municípios de Laguna e Paulo Lopes), conforme mostra a Tabela 8.

O município de Laguna conta com coleta de resíduos em $70 \%$ das residências (IBGE, 2000), cobertura que pode ser considerada baixa para garantir boas condições sanitárias no município, e ainda bem abaixo de Imbituba, que tem uma cobertura de $90 \%$.

TABELA 7 - ABASTECIMENTO DE ÁGUA POR DOMICÍLIO PARTICULAR PERMANENTE DO LITORAL SUL - SC

\begin{tabular}{l|c|c|c|c|c|c|c}
\hline & \multicolumn{9}{c}{ Forma de abastecimento de água } \\
\hline \multicolumn{1}{c|}{ Municípios } & Total de domicílios & \multicolumn{2}{c|}{ Rede geral } & \multicolumn{2}{c}{ Poço ou nascente } & Outros & $\%$ \\
\hline Paulo Lopes & ocupados & Número & $\%$ & Número & $\%$ & & \\
\hline Garopaba & 1.621 & 1.052 & 64,90 & 196 & 12,09 & 373 & 23,01 \\
\hline Imaruí & 3.755 & 2.193 & 58,40 & 915 & 24,37 & 647 & 17,23 \\
\hline Imbituba & 3.884 & 1.669 & 42,97 & 899 & 23,15 & 1.316 & 33,88 \\
\hline Laguna & 10.335 & 7.712 & 74,62 & 2.316 & 22,41 & 307 & 2,97 \\
\hline Jaguaruna & 14.243 & 9.896 & 69,48 & 3.344 & 23,48 & 1.003 & 7,04 \\
\hline Litoral Centro-Sul & 4.183 & 1.116 & 26,68 & 3.011 & 71,98 & 56 & 1,34 \\
\hline SC & 38.021 & 23.638 & 62,17 & 10.681 & 28,09 & 3702 & 9,74 \\
\hline
\end{tabular}

FONTE: Elaborada por Cataneo, S. com base em IBGE- Censo Demográfico, 2000.

TABELA 8 - COLETA DO LIXO POR DOMICÍLIO PARTICULAR PERMANENTE DO LITORAL SUL - SC

\begin{tabular}{l|c|c|c|c|c}
\hline \multicolumn{1}{c|}{ Municípios } & $\begin{array}{c}\text { Total de domicílios } \\
\text { ocupados }\end{array}$ & \multicolumn{4}{|c}{ Destino do lixo } \\
\hline & & Coletado & $\%$ & Outros & $\%$ \\
\hline Paulo Lopes & 1.621 & 1.139 & 70,27 & 482 & 29,73 \\
\hline Garopaba & 3.755 & 3.431 & 91,37 & 324 & 8,63 \\
\hline Imaruí & 3.884 & 1.347 & 34,68 & 2.537 & 65,32 \\
\hline Imbituba & 10.335 & 9.302 & 90,00 & 1033 & 10,00 \\
\hline Laguna & 14.243 & 9.999 & 70,20 & 4.244 & 29,80 \\
\hline Jaguaruna & 4.183 & 2.818 & 67,37 & 1.365 & 32,63 \\
\hline Litoral Centro Sul & 38.021 & 28.036 & 73,74 & 9985 & 26,26 \\
\hline SC & 1.498 .742 & 1.244 .660 & 83,05 & 254.082 & 16,95 \\
\hline
\end{tabular}

FONTE: Elaborada por Cataneo, S. com base em IBGE- Censo Demográfico, 2000. 
A questão do esgotamento sanitário é preocupante em todo o estado de Santa Catarina, onde a média de cobertura de redes de coleta de esgotos é de apenas $20 \%$ e o uso de fossas rudimentares representa $70 \%$ da solução adotada pelos domicílios. Essa questão fica ainda pior na região do litoral centro-sul. A Tabela 9 mostra os índices de esgotamento sanitário, conforme o tipo: rede de coleta pública, fossa rudimentar e séptica e outros, como o lançamento direto em rios, mares e lagos.

O município de Laguna tem apenas $20 \%$ dos domicílios atendidos por rede pública e $70 \%$ atendidos por fossas rudimentares, o que ainda significa que $10 \%$ da população não têm qualquer tipo de sistema de tratamento. Vale ressaltar índices baixíssimos em regiões como Paulo Lopes e Imaruí, onde, respectivamente, $14 \%$ e $20 \%$ da população não contam nem sequer com fossas rudimentares, lançando seus dejetos diretamente nos corpos hídricos da região. Fora Laguna, todos os outros municípios da região apresentam índices abaixo de $4 \%$ de cobertura de rede pública de esgoto.

O despejo de esgotos domésticos não tratados contendo poluentes em um curso d'água ou rede de drenagem, ou qualquer corpo hídrico, pode ocasionar sérios problemas à qualidade do meio ambiente e, conseqüentemente, trazer incômodos à população local.

A degradação ambiental na região não é exclusiva da poluição e contaminação dos recursos hídricos por esgotos domésticos. Existem também rejeitos provenientes de beneficiamento do carvão, que, além de refletirem na qualidade da água pela lixiviação e infiltração, tornam extensas áreas improdutivas, por causa da disposição da pirita no solo, contribuindo para a diminuição do $\mathrm{pH}$.

Os rios que chegam ao complexo lagunar, principalmente o Rio Tubarão, recebem efluentes contendo metais pesados provenientes das atividades de mineração (extração e beneficiamento do carvão), resíduos domésticos e industriais, agrotóxicos e fertilizantes utilizados na rizicultura. Essa poluição do complexo lagunar contribui para a diminuição do estoque de pescado e, conseqüentemente, para o empobrecimento da população dos municípios de Imaruí, Laguna e Imbituba.

\section{Lazer e turismo}

A região centro-sul conta, em sua história, com um forte atrativo turístico. O município de Laguna, fundado em 1676, tem aproximadamente 600 imóveis e monumentos tombados pelo Patrimônio Histórico Nacional, entre eles o Farol de Santa Marta, construído em 1981, que é o segundo do mundo em alcance, e o maior das Américas.

Praias extensas e menores, intercaladas a costões rochosos, diversas lagunas e montanhas com matas nativas, entre outros atrativos naturais, contribuem para um afluxo crescente de turistas e veranistas na região. Alguns municípios apresentam quase ou mais da metade de residências

TABELA 9- DOMICÍLIO PARTICULAR PERMANENTE, POR EXISTÊNCIA DE BANHEIRO OU SANITÁRIO E TIPO DE ESGOTAMENTO SANITÁRIO DOS MUNICÍPIOS DO LITORAL SUL/SC

\begin{tabular}{|c|c|c|c|c|c|c|c|c|c|}
\hline \multirow[b]{3}{*}{ Municípios } & \multirow[b]{3}{*}{$\begin{array}{c}\text { Total de } \\
\text { domicílios } \\
\text { ocupados }\end{array}$} & \multicolumn{8}{|c|}{ Existência de banheiro ou sanitário } \\
\hline & & \multicolumn{6}{|c|}{ Tinham } & $\begin{array}{l}\text { Não } \\
\text { tinham }\end{array}$ & \\
\hline & & $\begin{array}{c}\text { Rede geral } \\
\text { esgoto } \\
\text { / pluvial }\end{array}$ & $\%$ & $\begin{array}{c}\text { Fossa séptica e } \\
\text { rudimentar }\end{array}$ & $\%$ & $\begin{array}{c}\text { Vala, rio, } \\
\text { lago, mar e } \\
\text { outros }\end{array}$ & $\%$ & $\begin{array}{c}\text { Sem banheiro } \\
\text { ou sanitário }\end{array}$ & $\%$ \\
\hline Paulo Lopes & 1.621 & 7 & 0,43 & 1.318 & 81,31 & 227 & 14,00 & 69 & 4,26 \\
\hline Imbituba & 10.335 & 203 & 1,96 & 9.761 & 94,45 & 182 & 1,76 & 189 & 1,83 \\
\hline Laguna & 14.243 & 2.841 & 19,95 & 9.966 & 69,97 & 1.030 & 7,23 & 406 & 2,85 \\
\hline Jaguaruna & 4.183 & 170 & 4,06 & 3.821 & 91,35 & 151 & 3,61 & 41 & 0,98 \\
\hline Litoral Centro Sul & 38.021 & 3.326 & 8,75 & 31.356 & 82,47 & 2.385 & 6,27 & 954 & 2,51 \\
\hline $\mathrm{SC}$ & 1.498 .742 & 292268,00 & 19,50 & 1.077 .672 & 71,91 & 105.183 & 7,02 & 23.619 & 1,58 \\
\hline
\end{tabular}

FONTE: Elaborada por Cataneo, S. com base em IBGE - Censo Demográfico, 2000. 
destinadas a ocupação sazonal, como é o caso de Garopaba, com mais de $47 \%$ das residências desocupadas, e Jaguaruna, onde esse número chega a 59\% (Tabela 10).

Assim como na maioria dos lugares do mundo onde o turismo é uma importante fonte de renda, esta atividade também causa problemas ambientais em Santa Catarina. Os principais impactos sobre o meio ambiente costeiro causados pelo turismo são resultado da especulação imobiliária que induz construções de empreendimentos hoteleiros, marinas, segundas residências, além da sobreexploração de recursos vivos marinhos nas épocas de maior fluxo de turistas, resultado do aumento da demanda por frutos-domar nos restaurantes localizados no litoral.

\section{Espaços naturais protegidos}

As unidades de conservação no litoral de Santa Catarina caracterizam-se pelo grande número de pequenas áreas decretadas como tal por iniciativa dos municípios. Poucas unidades têm mais de 10.000 hectares, e uma delas protege quase exclusivamente ambientes marinhos (Reserva Biológica Marinha do Arvoredo). Outra unidade de conservação com mais de 10.000 hectares, o Parque Estadual da Serra do Tabuleiro, representa majoritariamente ambientes que estão fora da zona costeira, protegendo outras categorias de ecossistemas.

No entanto, a maior unidade de conservação costeira no Estado de Santa Catarina é a Área de Proteção Ambiental (APA) da Baleia Franca, criada por Decreto Federal em 14 de setembro de 2000. A APA abrange 156.100 hectares, com cerca de 130 quilômetros de extensão, e inclui todos os municípios do litoral centro-sul (IBAMA, 2006).

No entanto, o extremo sul do Estado merece atenção pela situação crítica dos ecossistemas e por estar virtualmente desprotegido. O norte, por outro lado, merece atenção especial pela boa situação de conservação dos ecossistemas e espécies, grande diversidade biológica, presença de inúmeras espécies ameaçadas e por ainda apresentar oportunidades de expandir a área protegida.

Chama-se a atenção para o baixo número de unidades de conservação no litoral centro-sul e para o fato de que as unidades de conservação existentes são áreas grandes que abrangem vários municípios.

Dentro dos ecossistemas protegidos por unidades de conservação, as praias, marismas e costões rochosos são os ecossistemas menos representados. Além das áreas na zona costeira que já são protegidas por alguma figura de unidade de conservação (Tabela 11), a Secretaria de Estado de Desenvolvimento Urbano e Meio Ambiente fez em 1999 (dados não publicados) um levantamento das áreas de remanescentes naturais do litoral catarinense e contabilizou 39 diferentes áreas. A Tabela 12 refere-se a essas áreas, locais que abrigam importantes e raros ecossistemas costeiros, mas que não são protegidas por unidades de conservação.

Como em todo o Brasil, os principais problemas das unidades de conservação em Santa Catarina são os referentes ao mau dimensionamento das áreas e falta de representatividade de alguns ecossistemas, falta de monitoramento e fiscalização das unidades de conservação, além de impactos sociais, deslocando populações locais para fora das áreas preservadas.

TABELA 10 - CONDIÇÃO DE OCUPAÇÃO DOS DOMICÍLIOS DO LITORAL CENTRO SUL - SC

\begin{tabular}{l|c|c|c|c|c|c}
\hline \multicolumn{1}{c|}{$\begin{array}{c}\text { Total de domicílios } \\
\text { particulares recenseados }\end{array}$} & $\begin{array}{c}\text { Domicílios } \\
\text { ocupados }\end{array}$ & $\%$ & $\begin{array}{c}\text { Domicílios não } \\
\text { ocupados }\end{array}$ & $\begin{array}{c}\text { Média de } \\
\text { moradores por } \\
\text { domicílio }\end{array}$ \\
\hline Paulo Lopes & 2.021 & 1.632 & 80,75 & 389 & 19,25 & 2,93 \\
\hline Garopaba & 7.210 & 3.771 & 52,3 & 3.439 & 47,7 & 1,83 \\
\hline Imaruí & 4.846 & 3.909 & 80,66 & 937 & 19,34 & 2,77 \\
\hline Imbituba & 14.459 & 10.356 & 71,62 & 4.103 & 28,38 & 2,47 \\
\hline Laguna & 21.593 & 14.267 & 66,07 & 7.326 & 33,93 & 2,20 \\
\hline Jaguaruna & 10.212 & 4.203 & 41,16 & 6.009 & 58,84 & 1,43 \\
\hline Litoral Centro Sul & 60.341 & 38.138 & 63,2 & 22203 & 36,8 & 2,97 \\
\hline SC & 1.818 .273 & 1.504 .693 & 82,75 & 313.580 & 17,25 & 2,95 \\
\hline
\end{tabular}

Fonte: Elaborada por Cataneo, S. com base em IBGE- Censo Demográfico, 2000. 
TABELA 11 - UNIDADES DE CONSERVAÇÃO NO LITORAL CENTRO-SUL DE SANTA CATARINA

\begin{tabular}{c|c|c|c}
\hline \multicolumn{1}{c|}{ REBIO } & Categoria & \multicolumn{1}{c|}{ Município } & Ambiente / ecossistema \\
\hline $\begin{array}{l}\text { Res. Biol. Da Praia do } \\
\text { Rosa }\end{array}$ & $\mathrm{M}$ & Imbituba & Mata Atlântica \\
\hline \multicolumn{1}{c|}{ Parque } & Categoria & \multicolumn{1}{c}{ Município } & Ambiente / ecossistema \\
\hline $\begin{array}{c}\text { Parque Est. da Serra do } \\
\text { Tabuleiro }\end{array}$ & $\mathrm{E}$ & $\begin{array}{l}\text { Imaruí, Garopaba, Paulo } \\
\text { Lopes, Palhoça, } \\
\text { Florianópolis }\end{array}$ & Mata Atlântica e costeira \\
\hline \multicolumn{1}{c|}{ APA } & Categoria & \multicolumn{1}{c}{ Município } & Ambiente / ecossistema \\
\hline Baleia Franca & U & $\begin{array}{l}\text { 9 municípios do litoral } \\
\text { central e centro-sul }\end{array}$ & $\begin{array}{l}\text { Águas Costeiras e } \\
\text { planície litorânea }\end{array}$ \\
\hline
\end{tabular}

$\mathrm{M}=$ Municipal, $\mathrm{E}=$ Estadual, $\mathrm{U}=$ União, $\mathrm{P}=$ Particular.

Fonte: Elaboração Scherer, M. com base em dados não publicados da SDM (1999).

TABELA 12 -ÁREAS REMANESCENTES DE ECOSSISTEMAS/AMBIENTES COSTEIROS DA REGIÃO CENTRO-SUL DE SANTA CATARINA (QUE NÃO ESTÃO COBERTOS POR ÁREAS DE CONSERVAÇÃO)

\begin{tabular}{c|l|l|l}
\hline & \multicolumn{1}{|c|}{ Descrição } & \multicolumn{1}{|c}{ Ecossistema } & \multicolumn{1}{|c}{ Município } \\
\hline 1 & Complexo costeiro da Praia do Siriú & $\begin{array}{l}\text { Costão rochoso e mata atlântica } \\
\text { lagoa, manguezal, dunas, restinga, } \\
\text { praia }\end{array}$ & Garopaba \\
\hline 2 & $\begin{array}{l}\text { Morros de Garopaba até praia da } \\
\text { Ferrugem }\end{array}$ & $\begin{array}{l}\text { Costão rochoso e mata atlântica } \\
\text { dunas e restinga }\end{array}$ & Garopaba \\
\hline 3 & Lagoas de Garopaba e Ibiraquera & Lagoa e estuário & Garopaba/ Imbituba \\
\hline 4 & Dunas de Ibiraquera e Ribanceira & Dunas, restinga & Imbituba \\
\hline 5 & $\begin{array}{l}\text { Dunas da Praia de Itapirubá, do Gi e do } \\
\text { Sol }\end{array}$ & $\begin{array}{l}\text { Dunas, costão rochoso e mata } \\
\text { atlântica, restinga, ilha }\end{array}$ & Imbituba/ Laguna \\
\hline 6 & Complexo Lagunar & Lagoas, manguezal, marismas & Laguna \\
\hline 7 & Planície úmida & Marismas e lagoas & Laguna \\
\hline 8 & Cabo de Santa Marta & Dunas, lagoas & Laguna \\
\hline 9 & Grande Restinga Sul do Estado & Dunas, lagoas, restinga & Jaguaruna, Içara \\
\hline 10 & $\begin{array}{l}\text { Complexo de Lagoas costeiras - Lagoa } \\
\text { dos Esteves }\end{array}$ & Lagoas, dunas, praias, restinga & Içara/ Araranguá \\
\hline
\end{tabular}

FONTE: Elaboração Scherer, M. com base em dados não publicados da SDM (1999). 


\section{A gestão costeira governamental do litoral catarinense}

O estado de Santa Catarina segue as legislações e resoluções federais em relação à proteção da zona costeira, e tem poucas leis próprias importantes no tocante à preservação do litoral. Nesse sentido, cabe destacar o Decreto Estadual n. ${ }^{\circ} 14.250$ de 5 de junho de 1981, uma legislação do estado de Santa Catarina que protege os ecossistemas costeiros.

Em Santa Catarina, assim como em todo o Brasil, a competência para ordenar e gerenciar a zona costeira passa por diferentes esferas. Assim, vários órgãos governamentais contam com políticas voltadas à gestão costeira.

O órgão ambiental federal Instituto Brasileiro de Meio Ambiente (Ibama) atua em áreas consideradas patrimônio da União, como, por exemplo, as terras de marinha. O Ibama também é fiscalizador do cumprimento da legislação ambiental.

A Fundação Estadual do Meio Ambiente (Fatma) atua como licenciadora das atividades em todo o estado e, por consequiência, na zona costeira. Possui uma sede administrativa localizada em Florianópolis e coordenadorias regionais no Estado. Criada em 1975, a Fatma tem como missão maior garantir a preservação dos recursos naturais do estado.

Já a Secretaria do Desenvolvimento Sustentável (SDS) conta com vários órgãos com influência direta no litoral catarinense. Entre estes, podem-se citar:

- Conselho Estadual de Meio Ambiente (Consema): delibera e orienta a Política Estadual de Meio Ambiente a partir do estabelecimento de normas, procedimentos, acompanhamentos e avaliação para o controle das atividades ambientais nas entidades vinculadas ou supervisionadas pelo Governo, para melhorar a qualidade ambiental.

- Câmara Técnica do Gerenciamento Costeiro: câmara vinculada ao Consema que tem por finalidade avaliar as ações do Gerco/SC.

- Gerco/SC: responsável pelo desenvolvimento e implantação do Programa Estadual de Gerenciamento Costeiro em Santa Catarina.

O estado de Santa Catarina, conforme previsto no Plano Nacional de Gerenciamento Costeiro (PNGC), instituído pela Lei 7.661, de 16/05/88, tem um Programa Esta- dual de Gerenciamento Costeiro (Gerco/SC). A Secretaria de Desenvolvimento Sustentável do Estado de Santa Catarina (SDS) é o órgão governamental responsável pela implantação desse programa.

Recentemente, o estado aprovou a Lei Estadual $n^{\circ}$ 13.553, que institui o Plano Estadual de Gerenciamento Costeiro. A equipe do Gerco/SC está trabalhando em um documento de regulamentação dessa lei.

$\mathrm{O} \mathrm{Gerco} / \mathrm{SC}$ tem as mesmas diretrizes e instrumentos que o Programa Nacional de Gerenciamento Costeiro: plano estadual e planos municipais de gerenciamento costeiro (PEGC e PMGC); sistema de informações da zona costeira (Sigerco); sistema de monitoramento ambiental da zona costeira (SMA); relatório de qualidade ambiental (RQA); e o zoneamento ecológico econômico costeiro (Zeec).

Em relação aos instrumentos de gestão, Santa Catarina tem parte da sua zona costeira detalhada no zoneamento ecológico econômico costeiro (Zeec), mas somente a região centro-norte tem o Zeec finalizado. O Zeec do litoral norte está sendo iniciado e a região centro-sul desenvolve estudos para o zoneamento da atividade de carcinicultura. No entanto, todos os Zeec carecem de marco legal que os torne efetivos.

Santa Catarina também é um dos poucos estados que têm o sistema de informações do Gerco (Sigerco) instalado, ainda que careça de dados e de pessoal treinado para utilizar os programas de computador necessários para a funcionalidade do Sigerco.

O sistema de monitoramento costeiro nesse estado é pouco desenvolvido, pois os parâmetros a serem monitorados não estão claros e não existe pessoal e infraestrutura adequada para a realização de tal monitoramento. Assim, os relatórios de qualidade ambiental também não são realizados, o que termina por prejudicar a elaboração dos relatórios nacionais de qualidade ambiental.

$\mathrm{Na}$ Tabela 13 mostram-se quais instrumentos de gestão estão implantados dentro do Gerco/SC.

Atualmente, as principais ações que estão sendo desenvolvidas pelo Gerco/SC são as seguintes:

- proposta de regulamentação da Lei Estadual de Gerenciamento Costeiro;

- zoneamento ecológico econômico na região norte do Estado;

- sistema de informações costeiras;

- zoneamento da maricultura na região centro-sul do Estado; 
TABELA 13 - SITUAÇÃO DE IMPLANTAÇÃO DOS INSTRUMENTOS DO GERCO/SC

\begin{tabular}{l|l|c|c}
\hline Fase de implantação & $\begin{array}{l}\text { Implantado e } \\
\text { operante }\end{array}$ & Em fase de implantação & $\begin{array}{l}\text { Sem data prevista de } \\
\text { implantação }\end{array}$ \\
\hline Instrumentos & & $\mathrm{X}$ & $\mathrm{X}$ \\
\hline PEGC & & $\mathrm{X}$ & \\
\hline SIGERCO & & $\mathrm{X}$ & $\mathrm{X}$ \\
\hline ZEEC & & & $\mathrm{X}$ \\
\hline RMA & & & \\
\hline
\end{tabular}

FONTE: Elaboração Scherer, M.

\section{Ações de gestão governamentais no litoral cen- tro-sul}

A gestão costeira do litoral centro-sul está baseada em um mosaico de ações governamentais de diferentes órgãos de planificação e execução.

Como uma das ações mais importantes para a ordenação dessa parte do litoral catarinense, cita-se a criação da APA da Baleia Franca no ano de 2000. Essa unidade de conservação abrange todos os municípios desse litoral na sua porção terrestre e marítima e os estudos para o zoneamento da atividade de carcinicultura no complexo lagunar da região de Laguna.

A APA da Baleia Franca permite um controle maior das atividades potencialmente degradadoras, pois o Ibama deverá ser ouvido no caso de implantação dessas atividades nos municípios que a compõem. Outra inovação dessa unidade de conservação é a contemplação de áreas marinhas e terrestres na mesma unidade de conservação, permitindo uma abrangência maior das ações de gestão. Uma vez que o Plano de Manejo da APA da Baleia Franca seja estabelecido, o litoral centro-sul contará com mais instrumentos de gestão.

$\mathrm{O}$ zoneamento da atividade de carcinicultura que vem sendo estudado pelo Gerco/SC da SDS é uma importante iniciativa, uma vez que essa atividade está em pleno desenvolvimento e ocupa grandes áreas das margens das lagoas.

A região também tem um Comitê de Bacia, o Comitê da Bacia Hidrográfica do Rio Tubarão. Este pode ser um importante agente na gestão dos recursos hídricos e conse- qüentemente da zona costeira relacionada à desembocadura do Rio Tubarão, como é o caso do complexo lagunar do centro-sul do Estado.

\section{Conclusões}

O litoral centro-sul do estado de Santa Catarina vem mantendo a tendência de urbanização com crescimento da densidade demográfica na maioria dos seus municípios.

As políticas públicas, legislação e ações administrativas deveriam acompanhar a demanda por ordenação do território que existe nessa região, em especial desenvolvimento urbano e carcinicultura. No entanto, problemas ambientais resultantes da falta de planejamento urbano e de gestão desse espaço estão se tornando cada vez mais evidentes na região do litoral centro-sul, em especial na região da cidade de Laguna.

Os sistemas de saneamento ambiental em assentamentos urbanos, de responsabilidade do poder público, apresentam uma realidade defasada entre a capacidade de atendimento e a demanda do crescimento demográfico nacional.

Esta carência tem sido umas das maiores causas de poluição de áreas urbanas e do meio ambiente de forma geral. A falta de equipamentos de saneamento ambiental está diretamente relacionada à baixa qualidade de vida da população no meio urbano e à fragilidade da saúde dessa população.

A poluição dos corpos hídricos da região por esgotamento doméstico, pesticidas e herbicidas advindos de cultivos agrícolas, por poluentes decorrentes da mineração de 
carvão e, mais recentemente, pela atividade de carcinicultura são tipos de impactos ambientais que afetam toda a região e também a área marinha.

Dessa forma, a adequação de um sistema de saneamento ambiental às necessidades atuais da população do litoral centro-sul e das projeções das demandas futuras decorrentes do desenvolvimento dessa região é fundamental para garantir a preservação do meio ambiente urbano e a qualidade de vida nas cidades.

Por outro lado, o crescimento urbano nas planícies costeiras na região de Laguna causa supressão de vegetação litorânea importante para a dinâmica dos ecossistemas costeiros. Em relação aos processos erosivos, essa supressão é especialmente danosa se causada na região de dunas frontais, desestabilizando o sedimento e podendo causar processos de erosão ou sedimentação.

Em relação aos ecossistemas costeiros, a perda da vegetação litorânea causa a irreversível perda de hábitats e a conseqüente perda de biodiversidade. A ocupação das planícies, sem infra-estrutura e planejamento adequados, juntamente com o déficit relacionado ao saneamento básico no município, tem levado a impactos ambientais significantes.

\section{Referências}

BITTENCOURT, A. C. S. P. et al. The marine formations of the coastal of the state of Bahia. In: INTERNATIONAL SYMPOSIUM ON COASTAL EVOLUTION IN THE QUATERNARY, 1978, São Paulo, IGCP, Project 61. Proceedings, n. 1, 1978. p. 232-253.

CARUSO, F. Jr. Mapa geológico do sudeste de Santa Catarina e texto explicativo. DNPM: Brasília, 1995.

COSTA, W. M. Levantamento e avaliação das políticas federais de transporte e seu impacto do uso do solo da região costeira. MMA - Programa Nacional do Meio Ambiente. Brasília, 1995.

DNPM. Texto explicativo para o mapa geológico do Estado de Santa Catarina. Florianópolis: $11^{\circ}$ Distrito do Departamento Nacional da Produção Mineral, Coordenadoria de Recursos Minerais da Secretaria da Ciência e Tecnologia, Minas e energia, 1987.
Para que o litoral centro-sul de Santa Catarina, em especial a região do complexo lagunar e a cidade de Laguna, continue seu desenvolvimento de maneira sustentável, é necessário que medidas de planejamento e gestão sejam colocadas em prática.

Algumas medidas podem ser eficazes para a melhoria da qualidade ambiental da região, tais como: melhoria do saneamento básico; planificação do desenvolvimento urbano; zoneamento e definição de critérios para atividade de maricultura, em especial a carcinicultura; desenvolvimento e implementação do Plano de Manejo da APA da Baleia Franca; seguimento da legislação ambiental, em especial as normas relacionadas à poluição de corpos hídricos e áreas de preservação permanente.

As ações de gestão devem ser realizadas de maneira integrada com as diversas iniciativas. Nesse contexto, o Programa Estadual de Gerenciamento Costeiro (Gerco/SC) aparece como o integrador dessas ações, e deve promover a interlocução entre os diversos atores e interesses sociais do litoral. O Gerco/SC tem esse papel e deve desempenhálo para que se caminhe para uma utilização racional dos recursos costeiros no litoral centro-sul do Estado de Santa Catarina.

FORTES, E.; DUARTE, G. M. A planície costeira da região de Biguaçu - SC: abordagens dos aspectos ambientais da bacia hidrográfica do rio Biguaçú. 1996. Dissertação (Mestrado) - Universidade Federal de Santa Catarina, Centro de Filosofia e Ciências Humanas.

GERCOS/SC. Nota técnica. SDM, Florianópolis, SC, 1999.

GERCOS/SC. Entendendo o processo de gerenciamento costeiro para o litoral de Santa Catarina. Secretaria de Estado do Desenvolvimento Social, Urbano e Meio Ambiente. Florianópolis, 2004.

GUZENSKI, A. L. C. S. Diagnostico sócio-econômico dos trabalhadores das fazendas de cultivo de camarão do município de Laguna/SC. 2000. Dissertação (Mestrado em Aqüicultura) - UFSC.

IBAMA. Disponível em: <http://www.ibama.gov.br>. Acesso em: 2006. 
INPH. Relatório do Instituto Nacional do Patrimônio Histórico. 1994.

IBGE. Instituto Brasileiro de Geografia e Estatística. Censo demográfico. 1996.

IBGE. Instituto Brasileiro de Geografia e Estatística. Censo demográfico. 2000.

LUCENA, L. M. F. Laguna: de ontem e hoje espaços públicos e vida urbana. 1998. Dissertação (Mestrado em Desenvolvimento Regional e Urbano) - Departamento de Geociências, UFSC.

MARTIN, L.; SUGUIO, K. Coastal quaternary deposits of the state of Paraná e Santa Catarina. In: INTERNACIONAL SYMPOSIUM ON SEA LEVEL CHANGES AND QUATERNARY SHORE LINES, 1986, São Paulo. Anais... São Paulo, 1986. 124 p.

MMA. Caracterização dos ativos ambientais em áreas selecionadas da zona costeira brasileira. Brasília: Ministério do Meio Ambiente, dos Recursos Hídricos e da Amazônia Legal-Secretaria de Implementação de Políticas e Normas Ambientais - Programa Nacional do Meio Ambiente, 1998.

MORAES, A. C. R. de. Os impactos da política urbana sobre a zona costeira. Ministério do Meio Ambiente, dos Recursos Hídricos e da Amazônia Legal. Brasília: Pax, 1995.

OLIVEIRA, D. A. G. Caracterização bio-sedimentologica e propostas de setorização das lagunas de Camacho, Garopaba do Sul e santa Marta, Santa Catarina, Brasil. 2004. Dissertação (Mestrado em Utilização e Conservação dos Recursos Naturais) - Departamento de Geociências, UFSC.

PETROBRAS. Diagnóstico ambiental oceânico e costeiro das regiões Sul e Sudeste do Brasil. v. 1-10. Coordenação Fundespa. Fundespa/Petrobras, 1994.
PNUD. Relatório de desenvolvimento humano (RDH). Disponível em: <http://www.pnud.org.br/idh/>. Acesso em: 2005.

PROJETO RECOS. Instituto do milênio. Disponível em: <http://www.mileniodomar.org.br/>. Acesso em: 2004.

PRONABIO - Programa Nacional de Biodiversidade. Brasíla: Ministério do Meio Ambiente e da Amazônia Legal (MMA), 1999.

SDM - Secretaria de Estado do Desenvolvimento Urbano e Meio Ambiente, Governo de Santa Catarina. Bacias hidrográficas de Santa Catarina: diagnóstico geral. Florianópolis, 1997.

SDM. Governo do Estado de Santa Catarina, Secretaria Estadual de Meio Ambiente e Desenvolvimento Urbano, atual SDS. Disponível em: <www.sds.sc.gov.br> Acesso em: 2001.

SIERRA de LEDO, B.; GRÉ, J. C. R.; SORIANO-SIERRA, E. Fishery production, anthropogenic and natural stress in Conceição Lagoon, Santa Catarina - Brazil. In: INTERNATIONAL SYMPOSIUM ON UTILIZATION OF COASTAL ECOSSYSTEMS: PLANNING, POLLUTION AND PRODUCTIVITY. 1989. n. 1. p. 485-496.

SUGUIO, K; MARTIN, L. Mecanismos de gênese das planícies sedimentares quartenárias do litoral do Estado de São Paulo. Ouro Preto, 1978. In: CONGRESSO BRASILEIRO DE GEOLOGIA.

VILLWOCK, J. A.; TOMAZELLI, L. J. Geologia costeira do Rio Grande do Sul. Nota explicativa para o mapa geológico em escala 1:1.000.000. Porto Alegre, 1996. Notas Técnicas n. 8 . 